\title{
Intraspecific functional diversity in hosts and its effect on disease risk across a climatic gradient
}

\author{
K. A. Garrett,${ }^{1,2,3,7}$ L. N. Zúñiga, ${ }^{4}$ E. Roncal,${ }^{5}$ G. A. Forbes,${ }^{2}$ C. C. Mundt,${ }^{3}$ Z. Su, ${ }^{1,8}$ and R. J. Nelson ${ }^{2,6}$ \\ ${ }^{1}$ Department of Plant Pathology, 4024 Throckmorton Plant Sciences Center, Kansas State University, Manhattan, Kansas 66506 USA \\ ${ }^{2}$ Centro Internacional de la Papa, Apartado 1558, Lima 12, Peru \\ ${ }^{3}$ Department of Botany and Plant Pathology, 2082 Cordley Hall, Oregon State University, Corvallis, Oregon 97331-2902 USA \\ ${ }^{4}$ Instituto Nacional de Investigación y Extensión Agraria, Huancayo, Peru \\ ${ }^{5}$ Instituto Nacional de Investigación y Extensión Agraria, Cajamarca, Peru \\ ${ }^{6}$ Department of Plant Pathology, Cornell University, Ithaca, New York 14853 USA
}

\begin{abstract}
The effects of host biodiversity on disease risk may vary greatly depending on host population structure and climatic conditions. Agricultural diseases such as potato late blight, caused by Phytophthora infestans, provide the opportunity to study the effects of intraspecific host diversity that is relatively well-defined in terms of disease resistance phenotypes and may have functional impacts on disease levels. When these systems are present across a climatic gradient, it is also possible to study how season length and conduciveness of the environment to disease may influence the effects of host diversity on disease risk. We developed a simple model of epidemic progress to evaluate the effects on disease risk of season length, environmental disease conduciveness, and host functional divergence for mixtures of a susceptible host and a host with some resistance. Differences in disease levels for the susceptible vs. resistant genotypes shifted over time, with the divergence in disease levels first increasing and then decreasing. Disease reductions from host diversity were greatest for high host divergence and combinations of environmental disease conduciveness and season length that led to moderate disease severity. We also compared the effects of host functional divergence on potato late-blight risk in Ecuador (long seasons), two sites in Peru (intermediate seasons) in El Niño and La Niña years, and the United States (short seasons). There was some evidence for greater disease risk reduction from host diversity where seasons were shorter, probably because of lower regional inoculum loads. There was strong evidence for greater disease reduction when host functional divergence was greater. These results indicate that consideration of season length, environmental conduciveness to disease, and host functional divergence can help to explain the variability in disease response to host diversity.
\end{abstract}

Key words: agroecology; density dependence; disease ecology; frequency dependence; functional diversity; genetic diversity; genotypic diversity; intraspecific diversity; Phytophthora infestans; plant pathology; potato late blight; Solanum tuberosum.

\section{INTRODUCTION}

Understanding the role of biodiversity in ecosystem function is a primary goal of ecology, with added urgency as biodiversity is diminishing in both wild and agricultural systems (Hooper et al. 2005). Several mechanisms for greater plant productivity as a function of greater plant diversity have been characterized (reviewed by Fridley 2001). Complementarity may increase productivity when species/genotypes use resources differently, so that competition between different types is lower than within types. Facilitation between types may occur such that one type makes environmental conditions more favorable for another type. A third mechanism for greater

Manuscript received 21 May 2008; revised 31 December 2008; accepted 9 January 2009. Corresponding Editor: S. K. Collinge.

7 E-mail: kgarrett@ksu.edu

8 Present address: Harvard School of Public Health, Boston, Massachusetts 02115 USA. productivity is the "sampling effect," the greater probability of incorporating highly productive species as more species are assembled in a community. The sampling effect underscores the importance of functional diversity. For many species, the abundance of pathogens and vectors and the degree to which the abiotic environment supports disease progress are important environmental drivers of productivity. In animal disease ecology, the mechanisms for effects of biodiversity mentioned above (reviewed by Fridley 2001) are often defined in terms of factors affecting transmission between individuals: diversity effects on the rate of encounter, the probability of transmission given an encounter, as well as the density of susceptible individuals, the recovery rate, and the death rate of infected individuals (Keesing et al. 2006). In plant disease ecology, encounters between host individuals are less relevant, especially since wind and water dispersal are key for many pathogens, and research has focused on the fact that pathogen reproduction tends to be dependent on host frequency and/or host density, so higher levels of 
host biodiversity will tend to reduce the pathogen population (e.g., Mitchell et al. 2002). Other mechanisms for biodiversity effects in plant disease ecology include induced resistance as a result of exposure to pathogens reproducing on other plant genotypes and changes in the microenvironment as a result of mixed plant architectures (Garrett and Mundt 1999, Finckh et al. 2000, Mundt 2002).

The role of intraspecific genetic diversity is receiving more focus in ecology, with studies of its effects on behavior, fitness components, productivity, responses to disturbance, invasibility, and other ecological functions (Hughes et al. 2008). The development of genetic and genomic tools to facilitate evaluation of intraspecific diversity has been rapid, so that even in natural systems genomic characterization is becoming easier (e.g., Whitham et al. 2006, Travers et al. 2007), and agricultural systems offer a wealth of these and other tools for characterization. Agricultural systems also offer the advantage that the functional role of many genetic features is understood, at least to a degree, and incorporating the effect of intraspecific functional diversity in models of biodiversity is an important next step. Furthermore, many frameworks for conceptualizing the effects of biodiversity are relevant to either intraspecific or interspecific diversity, so we adopt the use of the term "type" to indicate either a genotype or a species in parts of our text. Mason et al. (2005) developed the idea of "functional divergence," or the degree to which types differ in their use of niche space. They use nitrogen availability as one example of a definition for niche space. In agricultural cropping systems, human-plant commensalisms, niche space for plant types may be defined for the most part in terms of successful performance by human standards. One important dimension of the space is defined by resistance to disease. Functional diversity in disease resistance may be defined in detail when the different resistance genes of a host population, and their interactions with ambient pathogen populations, are well characterized. A simpler approach that may capture many system features is evaluation of functional divergence, defined as the range in disease risk experienced by the different host types, where host types may represent one or more species that have some degree of susceptibility even if they are highly resistant.

One of the most direct applications of these ideas is the development of crop mixtures in agriculture (Wolfe 1985, Mundt 2002); if susceptible types are mixed at a relevant scale with resistant or immune types, crop disease incidence and severity may be reduced. When placing research with agricultural mixtures in the context of the broad range of ecological studies, there are several interesting conceptual possibilities. Ecologists contrast "synthetic assemblage experiments," where combinations of types are assembled to represent different levels of diversity, and "removal experiments," in which particular types are removed from established communities (Diaz et al. 2003). Agricultural systems offer an interesting square peg for this round-hole definition, since all represent groups of species assembled by their human commensalists with greater or lesser insights into how best to maximize productivity in terms of human interests. Traditional agricultural systems that have evolved over time to include many types (e.g., Rhoades and Bebbington 1990) may be represented experimentally by a smaller number of types to facilitate experiments and, in some cases, economic systems. A striking example of the use of biodiversity in agriculture is the deployment of rice mixtures composed of a resistant, lower value genotype and a susceptible, higher value genotype, which has been very successful in China for reducing rice blast losses (Zhu et al. 2000, Leung et al. 2003). But the use of crop mixtures has often provided mixed results for disease management, with the magnitude of benefits varying widely (e.g., Garrett et al. 2001). The development of strategies for deployment of agricultural diversity for disease management requires a clear understanding of when the effects of host diversity will be small or substantial.

The functional divergence of plant types in terms of their disease resistance phenotypes, or the level of disease resulting from the combination of host genotype, abiotic environment, and ambient pathogen population characteristics, may help to explain differences in the impact of host diversity. A general hypothesis in the analysis of mixtures for disease management is that the greater the difference in disease resistance phenotypes between host types in a mixture, the greater the size of the effect of the mixture on disease severity will tend to be. Disease severity is often measured as the percentage of the maximum number of infections possible (Garrett and Mundt 1999, Phillips et al. 2005) because many plant pathogens, especially fungal plant pathogens, are not systemic but produce a large number of local lesions per plant. Models of the effects of mixtures on epidemics have generally addressed resistant and immune types (Leonard 1969, Mundt et al. 1986, van den Bosch et al. 1990, Skelsey et al. 2005), though sometimes in practice all types in a mixture may have some form of susceptibility. Our first hypothesis was that greater functional divergence, exemplified by mixtures in which types have greater differences in phenotypic resistance, would experience greater host-diversity effects for reduced late blight. In addition to overall levels of resistance, differences in particular components of resistance (i.e., resistance mechanisms that impact different life history traits of the pathogen) can influence epidemics in mixtures. Jeger $(1981 a, b)$ demonstrated how mixtures of particular resistance phenotypes can result in increased disease levels in mixtures. If one genotype is resistant based on reduced spore production per infection while another is resistant based on a reduced probability of infection per spore, the combination of these two genotypes may result in higher infection rates than if the genotypes are separated. The 
need to understand the effects of different levels and types of susceptibility motivated the development of a new model of the effects of mixtures of resistance types on disease risk described in this paper.

Plant disease risk is strongly influenced by the abiotic environment, as illustrated by the "plant disease triangle" of susceptible host, competent pathogen, and disease-conducive environment which, in combination, allows disease to develop (Madden et al. 2007). The abiotic environment has the potential to influence (1) the disease resistance phenotype of a particular host type, (2) the ratio of the levels of phenotypic disease resistance of the host population (functional divergence), and (3) the effect of diversity on disease resistance phenotypes. In the case of the Chinese rice mixtures for rice blast management, the microclimate experienced by the taller susceptible varieties is less humid and so less conducive to disease when the taller varieties are mixed with shorter resistant varieties (Zhu et al. 2005). Season length may be another important factor in disease risk; the compound-interest structure of many epidemics (Madden et al. 2007) results in large increases in inoculum load at the end of a season. Where season length is longer, there will tend to be higher local and regional risk for diseases that are aerially dispersed. Season length can be a function of many factors; for example, for voles the beginning of a season may be a function of previous population sizes, generating population cycles (Smith et al. 2006). For plant diseases, the beginning and end of a season are generally defined by the occurrence of disease-conducive weather, often characterized by appropriate temperatures and levels of humidity or dew, and by the regional availability of susceptible hosts. The complexity of the relationship between environment and biodiversity effects is another motivation for developing our new model, incorporating the effects of environmental conditions such as season length on the relationship between biodiversity and disease risk. Our second hypothesis was that longer seasons may reduce the effects of biodiversity on disease risk.

In addition to our general model of biodiversity effects on disease risk, we address empirical studies of the pathogen Phytophthora infestans, causal agent of potato late blight (see Plate 1). Phytophthora species are infamous as forest pathogens that have proven extremely difficult to manage (reviewed in Hansen 2008): $P$. ramorum causing sudden oak death that threatens many plant species in temperate forests, $P$. lateralis infecting Port Orford cedars, and $P$. cinnamomi, a generalist pathogen destroying endemic plant species in Australian forests and elsewhere. P. infestans was the cause of potato losses in the Irish potato famine and recently more virulent and more pesticide resistant genotypes have increased problems with this pathogen globally (Fry and Goodwin 1997). P. infestans causes huge crop losses and requires massive quantities of pesticides for management in regions where many farmers have few resources to purchase pesticides and limited training for their safe use (Crissman et al. 1998). Improved management strategies may have very large cumulative effects on pesticide loads in sensitive environments, and important effects on regional inoculum loads. It is common to observe disease foci in fields infected by $P$. infestans in temperate regions, where initially small foci spread as the pathogen is dispersed onto neighboring plants by wind and/or rain-splash (Zwankhuizen et al. 1998). In contrast, in tropical regions such as around our research sites near Quito, Ecuador, it appears that heavy regional inoculum loads result in more spatially dispersed and more frequent infections (G. A. Forbes and K. A. Garrett, personal observation), probably through lift of spores into larger weather systems and subsequent spore showers.

The use of potato genotype mixtures has shown potential as a management component for late blight in the United States (Garrett and Mundt 2000b) and France (Andrivon et al. 2003), but did not have as important an effect near Quito, Ecuador, except at a site distant from other potato production (Garrett et al. 2001) or when combined with fungicide use (Pilet et al. 2006). Environmental differences between the sites where potato mixtures were evaluated for late blight management may be important for explaining the relative utility across the sites. At Quito, near the equator, potatoes are grown year round and the level of outside inoculum that enters a given field is likely to be high (Lima et al. 2009). Moving from Cajamarca in the north of Peru to Huancayo in central Peru, potato production becomes more seasonal and it would be expected that the level of regional inoculum would decline. Under the hypothesis that longer seasons reduce the effects of biodiversity on disease risk, a smaller host-diversity effect would be observed at Cajamarca sites than at the more southerly Huancayo sites. Potato late blight offers the ability to study intraspecific functional diversity using characterized genotypes in experiments across a climatic gradient from South to North America.

To address these hypotheses about the effects of host functional divergence and climate and develop a better general understanding of the effects of host diversity, our first objective was to develop a simple model of the effects of host diversity on disease risk that incorporates these effects. Our second objective was to determine the effect of host diversity on potato late blight severity (as measured by the percentage of diseased leaf area) in a shorter season region as compared with a longer season region of Peru. Our third objective was to compare the effects of host diversity at these Peruvian sites with previously published results for sites in the United States and Ecuador and to determine to what extent the hostdiversity effect can be predicted by functional divergence, in terms of the ratio of the level of resistance in the host genotypes, and by the climate, in terms of the length of the growing season and by inference the regional inoculum load. 
TABle 1. Notation and abbreviations.

\begin{tabular}{|c|c|}
\hline Variable & Definition \\
\hline$c_{\mathrm{r}}$ & $\begin{array}{l}\text { reduction in inoculum production per infection } \\
\text { for the partially resistant type relative to the } \\
\text { susceptible type }\end{array}$ \\
\hline$D_{\mathrm{r} t}$ & disease severity at time $t$ for the resistant type \\
\hline$D_{\mathrm{s} t}$ & disease severity at time $t$ for susceptible type \\
\hline$D_{t}$ & disease severity, or percentage infection, at time $t$ \\
\hline$p_{\mathrm{r}}$ & proportion of plants of the resistant genotype \\
\hline$p_{\mathrm{s}}$ & proportion of plants of the susceptible genotype \\
\hline$R$ & rate of disease increase \\
\hline$R_{\mathrm{r}}$ & rate of disease increase for the resistant variety \\
\hline & rate of disease increase for the susceptible variety \\
\hline RMR & $\begin{array}{l}\text { relative mixture response: disease severity in a } \\
\text { mixture divided by the weighted mean severity } \\
\text { in monocultures of the component types }\end{array}$ \\
\hline$S$ & initial infection level in the susceptible type \\
\hline
\end{tabular}

\section{Materials And Methods}

\section{Conceptual model of host functional diversity effects}

The logistic equation is commonly used as a simple model for the development of an epidemic subject to a carrying capacity (Madden et al. 2007). Here we use a discrete logistic model to describe disease severity (e.g., percentage of leaf area infected in a population of plants) over time. Because of the modular nature of many plant structures and plant responses to disease, individual plants are not tracked in the model. In this context, we use the following notation:

$$
D_{t+1}=D_{t}+R \times D_{t}\left[1-\left(D_{t} / 100\right)\right]
$$

where $D_{t}$ indicates the percentage of infection at time $t$ and $R$ indicates the rate of increase for disease (Table 1). Thus, the percent infection after one pathogen generation is modeled as the percent infection in the prior generation plus new infections that are produced at a rate $R$ from the available infections $\left(D_{t}\right)$, with the rate of new infections scaled down proportionately as the percentage of infection increases. Suppose two different host types are present in a mixture and infection in each is tallied separately, though inoculum is assumed to mix completely between the types. In the simplest mixture, one type is susceptible while the other is immune. In that case, infection occurs only on the susceptible type and can be modeled as

$$
D_{\mathrm{s} t+1}=D_{\mathrm{s} t}+R_{\mathrm{s}}\left(p_{\mathrm{s}} \times D_{\mathrm{s} t}\right)\left[1-\left(D_{\mathrm{s} t} / 100\right)\right]
$$

where $p_{\mathrm{s}}$ indicates the proportion of the hosts that are of the susceptible type, indicated by the subscript s. A reduction in disease in such simple mixtures occurs because only the proportion $p_{\mathrm{s}}$ of inoculum produced by the susceptible type will cause disease on the susceptible type while the other inoculum will be "wasted" by landing on the immune type.

For the case of a mixture of two host types of differing levels of susceptibility, the same model is applicable with an adaptation to the expression for inoculum availability. We modeled the percentage of infection in a partially resistant type as follows:

$$
\begin{aligned}
D_{\mathrm{r} t+1}=D_{\mathrm{r} t}+ & R_{\mathrm{r}}\left[\left(c_{\mathrm{r}} \times p_{\mathrm{r}} \times D_{\mathrm{r} t}\right)+\left(p_{\mathrm{s}} \times D_{\mathrm{s} t}\right)\right] \\
& \times\left[1-\left(D_{\mathrm{r} t} / 100\right)\right]
\end{aligned}
$$

where $c_{\mathrm{r}}$ denotes the reduction in inoculum production per infection for the partially resistant type relative to the susceptible type. Reduction in inoculum production per infection is one component of resistance out of several, and often is subsumed within the overall rate of increase $R_{\mathrm{r}}$, but here we have separated it to study its impact. The corresponding model for the percentage infection in the susceptible type is

$$
\begin{aligned}
D_{\mathrm{s} t+1}=D_{\mathrm{s} t}+ & R_{\mathrm{s}}\left[\left(c_{\mathrm{r}} \times p_{\mathrm{r}} \times D_{\mathrm{r} t}\right)+\left(p_{\mathrm{s}} \times D_{\mathrm{s} t}\right)\right] \\
& \times\left[1-\left(D_{\mathrm{s} t} / 100\right)\right] .
\end{aligned}
$$

For each type of host, the inoculum level produced locally (no regional inoculum is incorporated in this model) and available for producing new infections at time $t+1$ is

$$
\left(c_{\mathrm{r}} \times p_{\mathrm{r}} \times D_{\mathrm{r} t}\right)+\left(p_{\mathrm{s}} \times D_{\mathrm{s} t}\right)
$$

Evaluations of the effects of mixed types for disease risk can be based on at least two different criteria. First, if disease severity in the mixture is lower than the severity of each of the individual types when growing separately, there is a clear reduction in disease risk. This level of benefit might only be expected if more than one type is susceptible and pathogen populations infecting the different types are fairly distinct, so that there is a benefit to more than one type rather than a benefit only to the most susceptible type. This might be the scenario for different host species that do not share pathogen species, or for different genotypes within a host species that have different major genes for resistance that effectively partition the pathogen species into subpopulations. Second, disease severity in the mixture may be compared to the weighted mean of disease severity in the component types when growing individually. This is a measure of whether "local mixing" results in disease reduction, assuming the same types are grown together or apart. We take this approach to evaluating the effects of host mixtures, defining the relative mixture response (RMR) as the disease severity in the mixture divided by the weighted mean disease severity of the mixture component types grown individually. For example, if a mixture includes $25 \%$ type $\mathrm{A}$ and $75 \%$ type $\mathrm{B}$, the denominator of the RMR would be 0.25 times the disease severity of type A grown alone plus 0.75 times the disease severity of type B grown alone. If the RMR is greater than one, that indicates higher disease severity in the mixture than would have occurred if the plant types had grown separately. RMR less than one indicates lower disease severity in the mixture than would have occurred for plant types grown separately, and a potential benefit in agricultural systems.

This linked logistic model includes the implicit assumption that inoculum is limiting. This feature has two important implications. First, the starting value for 
TABLE 2. Sites included in the study of host functional divergence effects on potato late blight risk near Huancayo and Cajamarca, Peru.

\begin{tabular}{lcccc}
\hline \hline \multicolumn{1}{c}{ Site } & $\begin{array}{c}\text { Altitude } \\
\text { (m above sea level) }\end{array}$ & Years & Abbreviation & Planting date \\
\hline Aymará (Huancayo) & 3700 & $1997-1998$ & H-A98 & 25 Oct 1997 \\
Pazos (Huancayo) & 3600 & $1997-1998$ & H-P98 & 24 Oct 1997 \\
Pazos (Huancayo) & 3600 & $1998-1999$ & H-P99 & 11 Nov 1998 \\
Sicaya (Huancayo) & 3300 & $1998-1999$ & H-S99 & 12 Nov 1998 \\
La Encañada (Cajamarca) & 3050 & $1997-1998$ & C-E98 & 12 Nov 1997 \\
Porcon Alto (Cajamarca) & 3400 & $1997-1998$ & C-P98 & 13 Nov 1997 \\
Santa Clotilde (Cajamarca) & 3050 & $1998-1999$ & C-S99 & 24 Nov 1998 \\
\hline
\end{tabular}

infection is important in determining epidemic progress. In our model we treated the starting infection level in the susceptible type as a model parameter, $S$. For an immune type, no infection is possible. For a partially resistant type, the starting value was $\left(R_{\mathrm{r}} / R_{\mathrm{s}}\right) \times S$. Second, limiting inoculum makes the production of inoculum within the two crop types important, as expressed in Eq. 5. Higher regional inoculum levels will tend to produce higher starting values for infection processes and to reduce the importance of the function in Eq. 5 by adding a large additional source of inoculum through immigration throughout the growing season (the latter effect is not illustrated).

Since even this simple model structure allows for a large number of parameter combinations, we selected representative parameters to ask the following questions:

1) How do changes in conduciveness of the environment to disease, expressed through proportional increases in $R_{\mathrm{S}}$ and $R_{\mathrm{r}}$, affect the ratio of the disease resistance phenotypes for the two host types (the functional divergence)? And, how do changes in the starting infection level affect the ratio of disease resistance phenotypes for the two host types?

2) For the simplest form of mixture, a susceptible type mixed with an immune type, how does the RMR change over the course of the season?

3) For a mixture of a susceptible and a partially resistant type, how does the RMR change over the course of the season?

4) With regard to a mixture of a susceptible and a partially resistant type:

a) How does the overall level of resistance $\left(R_{\mathrm{S}}, R_{\mathrm{r}}\right.$, and $c_{\mathrm{r}}$ ) affect the RMR?

b) How does the ratio of susceptibility $\left(R_{\mathrm{S}}\right.$ vs. $\left.R_{\mathrm{r}}\right)$ of the types affect the RMR?

c) How does resistance expressed through reductions in $R_{\mathrm{r}}$ vs. resistance expressed through reductions in $c_{\mathrm{r}}$ affect the RMR?

5) In general:

a) How do these processes change when $R_{\mathrm{s}}$ and/or $R_{\mathrm{r}}$ both increase as a result of a more diseaseconducive environment?

b) How do these processes change when the starting infection percentage $S$ is higher?

c) How are these processes affected by season length, or the number of pathogen generations?

\section{Field studies in Huancayo and Cajamarca, Peru}

For the analysis of host-diversity effects on potato late blight, sites in farmers' fields were established near Huancayo $\left(12^{\circ} \mathrm{S}, 75^{\circ} \mathrm{W}\right)$ and Cajamarca $\left(7^{\circ} \mathrm{S}, 78^{\circ} \mathrm{W}\right)$, Peru, during the 1997-1998 (El Niño, conducive to disease) and 1998-1999 (La Niña, less conducive to disease) field seasons (Table 2). The sites near Huancayo were at a higher altitude than the sites near Cajamarca, in addition to being further south of the equator.

Mixture plots were planted in $25 \%$ of a susceptible variety and $75 \%$ of a more resistant variety, with the varieties arranged systematically to maximize the distance between susceptible varieties. At each site, two different mixtures were planted along with the single genotype stands of the component varieties (Table 3). Because of seed tuber limitations, the same mixtures could not be planted at every site during the first season. Research plots were arranged in a randomized complete block design with four replicates. Plots were $4 \times 4 \mathrm{~m}$, consisting of 12 plants in each of four $1 \mathrm{~m}$ wide rows. The planting density and the proportion of susceptible genotypes were selected to match experiments in the United States and Ecuador, since both can influence the size of host diversity effects (Garrett and Mundt 2000a). Plots were spaced at least $4 \mathrm{~m}$ apart from each other on all sides and borders were planted with oats (Avena sativa) near Huancayo and rye (Secale cereale) near Cajamarca to reduce movement of inoculum between plots. To allow the plants to become established before the epidemic began, protective fungicides were applied at the beginning of the season. All inoculum was naturally occurring and epidemics began late in the $\mathrm{La}$ Niña year because of the unusually dry conditions.

Percentage of foliar disease severity was evaluated weekly using visual estimates, separately for the cultivars in mixtures as well as in the single-genotype plots. While different cultivars can generally be distinguished visually, individual plants of a particular cultivar often intertwine, so that visual estimates were based on the plot as a whole rather than individual plant evaluations. When plants died, their diseased foliage was retained in the evaluation of disease severity. The area under the disease progress curve (AUDPC; Madden et al. 2007) for each site was analyzed separately in an analysis of variance (AOV). The following linear model was fit to the data for each site-year combination: 
TABLE 3. Potato cultivar mixtures included in the study of host functional divergence effects on potato late blight at sites near Huancayo (H) and Cajamarca (C), Peru; Quito, Ecuador; and Corvallis, Oregon, USA.

\begin{tabular}{|c|c|c|c|}
\hline \multicolumn{2}{|c|}{ Potato cultivar mixture } & \multirow[b]{2}{*}{ Sites† } & \multirow[b]{2}{*}{$\begin{array}{l}\text { Functional } \\
\text { divergencet }\end{array}$} \\
\hline $\begin{array}{l}\text { Resistant } \\
\text { component }\end{array}$ & $\begin{array}{l}\text { Susceptible } \\
\text { component }\end{array}$ & & \\
\hline \multicolumn{4}{|l|}{ Peru } \\
\hline \multirow[t]{4}{*}{$75 \%$ Kory } & $25 \%$ Liberteña & H-P98 & 1.14 \\
\hline & & H-A98 & 0.88 \\
\hline & & C-E98 & 0.87 \\
\hline & & C-P98 & 2.67 \\
\hline $75 \%$ Chagllina & $25 \%$ Yungay & H-A98 & 0.17 \\
\hline $75 \%$ Chagllina & $25 \%$ Tomasa & H-P98 & 1.46 \\
\hline $75 \%$ Perricholi & $25 \%$ Tomasa & C-E98 & 0.85 \\
\hline \multirow[t]{4}{*}{$75 \%$ Amarilis } & $25 \%$ Yungay & C-P98 & 2.54 \\
\hline & & H-P99 & 2.46 \\
\hline & & $\mathrm{H}-\mathrm{S} 99$ & 2.35 \\
\hline & & C-S99 & 0.79 \\
\hline \multirow[t]{3}{*}{$75 \%$ Amarilis } & $25 \%$ Tomasa & H-P99 & 3.40 \\
\hline & & $\mathrm{H}-\mathrm{S} 99$ & 3.13 \\
\hline & & C-S99 & 0.98 \\
\hline \multirow[t]{3}{*}{$75 \%$ Kory } & $25 \%$ Tomasa & H-P99 & 2.77 \\
\hline & & H-S99 & 3.65 \\
\hline & & C-S99 & 1.00 \\
\hline \multirow[t]{3}{*}{$75 \%$ Kory } & $25 \%$ Yungay & H-P99 & 1.84 \\
\hline & & $\mathrm{H}-\mathrm{S} 99$ & 2.87 \\
\hline & & C-S99 & 0.80 \\
\hline \multicolumn{4}{|l|}{ Ecuador } \\
\hline \multirow[t]{3}{*}{$75 \%$ Sta Catalina } & $25 \%$ Uvilla & ESC98 & 0.31 \\
\hline & & IASA98 & 0.18 \\
\hline & & CADET98 & 0.55 \\
\hline \multicolumn{4}{|l|}{ USA } \\
\hline \multirow[t]{4}{*}{ 75\% A90586-11 } & $25 \%$ Red & FOC97 & 1.44 \\
\hline & LaSoda & GEN97 & 1.49 \\
\hline & & FOC98 & 2.23 \\
\hline & & GEN98 & 2.18 \\
\hline
\end{tabular}

$\uparrow$ Site abbreviations are as defined in Table 2.

$\$$ Reported as $\log _{10}$ (AUDPC[sus]/AUDPC[res]), where AUDPC[sus] is the mean AUDPC in single-genotype stands of the susceptible mixture component and AUDPC[res] is the mean AUDPC in single genotype stands of the resistant mixture component; AUDPC is area under the disease progress curve.

$$
x_{i j}=\mu+\tau_{i}+\beta_{j}+\varepsilon_{i j}
$$

where $x_{i j}$ is the AUDPC for the $i j$ th experimental plot, $\tau_{i}$ is the effect of the $i$ th treatment $(i=1, \ldots, 8$ in 1997$1998 ; i=1, \ldots, 12$ in 1998-1999), $\beta_{j}$ is the effect of the $j$ th block $(j=1, \ldots, 4)$, and $\varepsilon_{i j}$ is the residual error. During the 1997-1998 season, there were four single-genotype treatments and two mixture treatments; during the 19981999 season, there were four single-genotype treatments and four mixture treatments. Genotypes were evaluated separately within the mixtures and overall disease severity was estimated as the weighted mean of severity for the components. Because there was a tendency for the variance of the response to increase with the mean response across treatments, the model was fit using weighted least squares. Each treatment was weighted with the inverse of the estimated variance for that treatment at that site. Percentage of severity in mixture was compared to percent severity in monoculture for each mixture component of each mixture using planned linear contrasts. For the 1998-1999 season, during which each cultivar appeared in two different mixtures, the percent severity for each component in those mixtures was also compared. For example, the percent severity for the cultivar Yungay was compared for Yungay in a mixture with Amarilis and Yungay in a mixture with Kory.

\section{Comparison of host diversity effects in Peru, United States, and Ecuador}

We also considered the results of the studies near Cajamarca and Huancayo in combination with results from studies of host-diversity effects on potato late blight near Corvallis, Oregon, USA (Garrett and Mundt 2000b), and near Quito, Ecuador (Garrett et al. 2001) (Table 4). From the studies in Peru, we had 20 mixture-site-year combinations. We selected the treatment from the Quito study that was most directly analogous to the Peruvian treatments: a mixture of $75 \%$ Santa Catalina (resistant) and $25 \%$ Uvilla (susceptible). This mixture was studied at three different sites near Quito. The Corvallis study was of a mixture of 75\% A90586-11 (resistant breeding selection) and 25\% susceptible Red LaSoda (susceptible). This mixture was studied for two imposed inoculum patterns (focal and general) in two different years near Corvallis, for a total of four inoculum pattern-year combinations. We used this set of data to evaluate how well the following two parameters predict the magnitude of host-diversity effects.

First, we considered how the season length, and so the likely level of regional inoculum, may have influenced the host-diversity effect, along with the weather condi-

TABLE 4. Ranking of research sites in terms of seasonality and other features expected to contribute to regional inoculum load, where a ranking of 1 indicates the highest estimated regional inoculum load.

\begin{tabular}{clcll}
\hline \hline Rank & \multicolumn{1}{c}{ Site } & $\begin{array}{c}\text { Regional abundance } \\
\text { of host }\end{array}$ & \multicolumn{1}{c}{ Length of available growing season } & $\begin{array}{c}\text { Year-specific } \\
\text { climatic characteristics }\end{array}$ \\
\hline 1 & Quito, Ecuador & high (low at one site) & year-round (at equator) & \\
2 & Cajamarca, Peru (1998) & high & medium (lower altitude, near equator) & El Niño year (wet) \\
3 & Cajamarca, Peru (1999) & high & medium (lower altitude, near equator) & La Niña year (dry) \\
4 & Huancayo, Peru (1998) & high & short (higher altitude, further from equator) & El Niño year (wet) \\
5 & Huancayo, Peru (1999) & high & short (higher altitude, further from equator) & La Niña year (dry) \\
6 & Corvallis, USA & low & short $\left(\sim 45^{\circ}\right.$ N) & \\
\hline
\end{tabular}

Note: The Peruvian sites are distinguished by year because of the large interannual difference in environmental conduciveness to disease due to El Niño effects. 

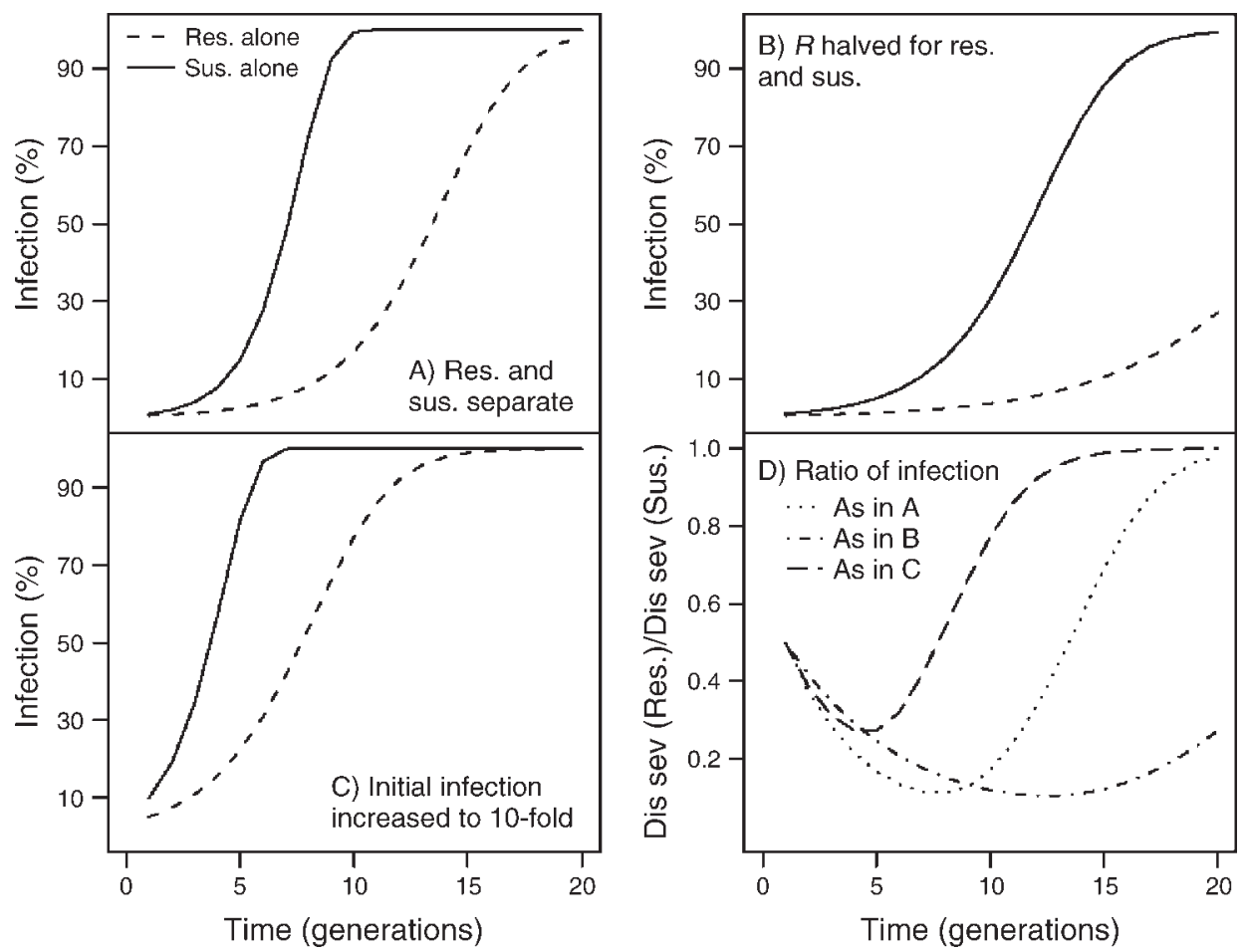

FIG. 1. (A-C) Model disease progress curves for three epidemic scenarios in which host types grow separately without inoculum exchange, and (D) a comparison of how the ratio of disease resistance phenotypes (functional divergence) changes with increasing pathogen generations for the two resistance types in each scenario. In each case, the ratio of the disease genotype is unchanged, illustrating the potential influence of environmental conditions and time of sampling on functional divergence. Time is measured in pathogen generations. (A) Reference epidemics for separate resistant (Res.) and susceptible (Sus.) types (rate of infection: $R_{\mathrm{S}}=1, R_{\mathrm{r}}=0.5$; initial infection level in the susceptible type: $S=1$ ). (B) Separate epidemics with rate of disease progress for both types reduced by half, such as might be expected for less disease-conducive abiotic conditions $\left(R_{\mathrm{s}}=0.5, R_{\mathrm{r}}=0.25, S=1\right)$. (C) Separate epidemics with same growth rates as in (A) but with the initial infection level increased 10 -fold $\left(R_{\mathrm{S}}=1, R_{\mathrm{r}}=0.5, S=\right.$ 10). (D) Time series of the ratio of disease severity in the separate resistant type [Dis sev (Res.)] over disease severity in the separate susceptible type [Dis sev (Sus.)] for scenarios A-C.

tions of the year being studied (Table 4). For this analysis, we ranked the locations, in order of increasing season length/predicted regional inoculum levels, as Corvallis, Huancayo, Cajamarca, and Quito. In addition, Huancayo's greater altitude makes seasonality relatively more apparent there. For comparisons of years, we assumed that drier years would experience lower inoculum levels. For Huancayo and Cajamarca, the 1998-1999 La Niña season was drier than the 1997-1998 El Niño season. Note that our ranking of the predicted inoculum level in, for example, a wet year in Corvallis compared to a dry year in Huancayo is arbitrary, but the rankings should generally reflect the trend in inoculum loads.

Second, we considered the influence of the difference in resistance between the two mixture components (the functional divergence). Because the functional divergence varied from site to site, we expressed this variable as the ratio of the AUDPC for the susceptible potato genotype grown alone over the AUDPC for the resistant potato genotype grown alone. Because the influence of changes in this variable on the RMR is likely to be greatest at low values of the ratio, we considered the
RMR as a function of $\log _{10}$ (AUDPC for susceptible/AUDPC for resistant). We compared this measure of functional divergence and the seasonality index as predictors of the RMR in a regression analysis.

\section{RESULTS \\ Model predictions}

Under our model, disease severity in single host type populations progresses following a logistic curve to approach $100 \%$ severity (Fig. 1). When a partially resistant type has a rate of increase of $R_{\mathrm{r}}=0.5$, half the rate of the susceptible $\left(R_{\mathrm{S}}=1\right)$, the number of pathogen generations required to reach $100 \%$ disease severity is doubled from about 10 to about 20, for a low initial infection rate $(S=1)$. When the rate of increase of both susceptible and partially resistant types is reduced by half $\left(R_{\mathrm{r}}=0.25, R_{\mathrm{S}}=0.5\right)$, infection in the susceptible type takes twice as many generations to reach $100 \%$ severity and infection in the resistant type develops slowly enough that there might be no important effect on productivity for typical agricultural pathogens that might only experience 5-10 or fewer generations per 
A) Sus. and immune res.

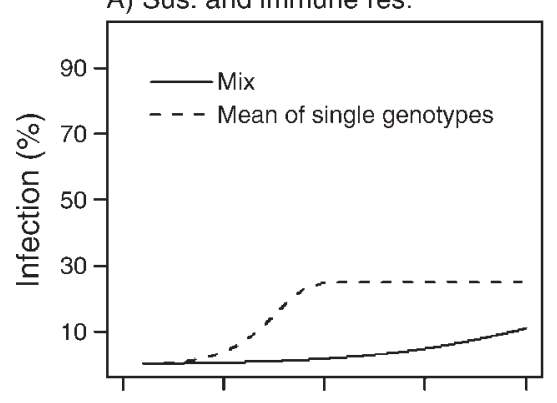

B) Increased $R$ for sus.

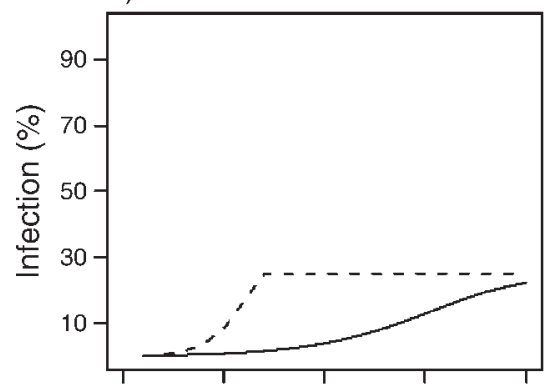

C) Increased initial infection

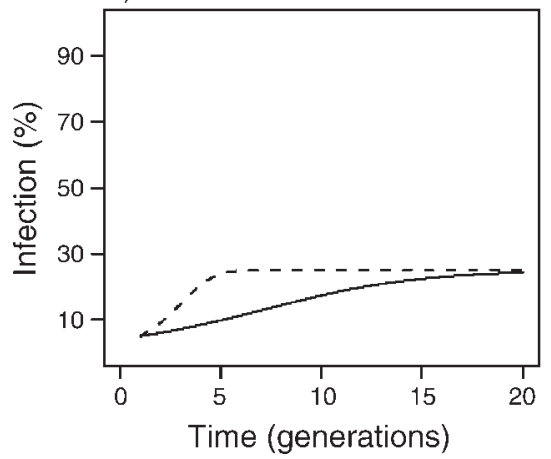

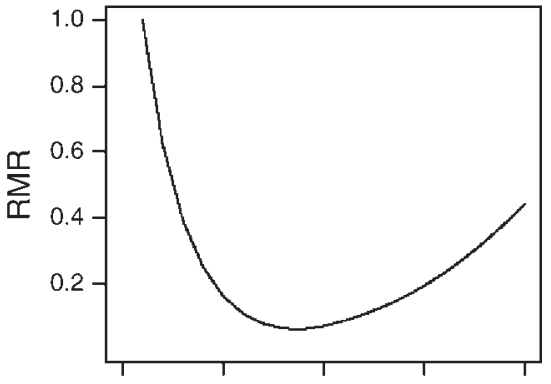
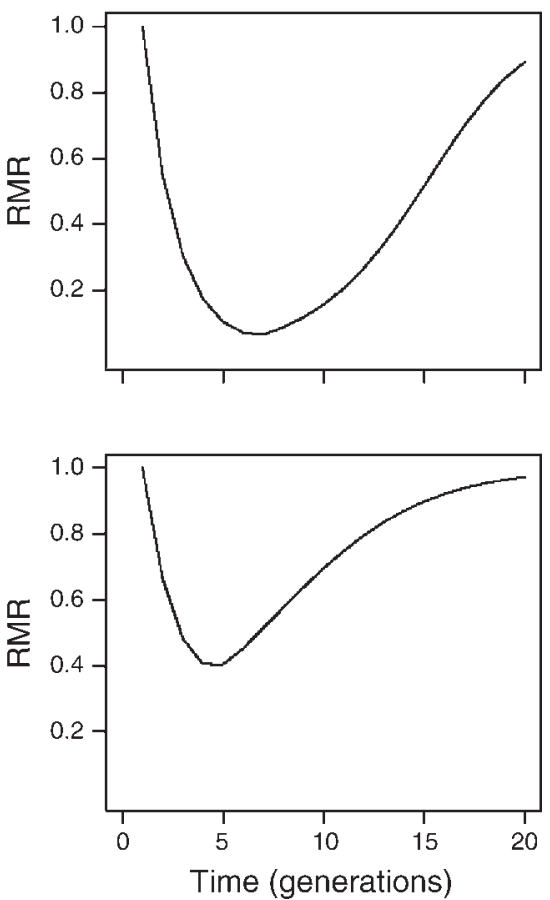

FIG. 2. Model disease progress over time and corresponding time series of the relative mixture response (RMR) for three scenarios based on a simple host mixture of a susceptible type and immune type. The lower the RMR, the greater is the disease reduction due to mixing. (A) Reference parameter combination $\left(R_{\mathrm{s}}=1, p_{\mathrm{s}}=0.25\right.$ [proportion of plants of the susceptible genotype], $S=1)$. (B) Increased rate of disease progress in the susceptible population $\left(R_{\mathrm{s}}=1.5, p_{\mathrm{s}}=0.25, S=1\right)$. (C) Parameters as in panel (A), but with increased initial infection level $\left(R_{\mathrm{s}}=1, p_{\mathrm{s}}=0.25, S=20\right)$.

season. When the initial infection rate is substantially higher $(S=10$ as compared to $S=1)$, both types experience substantial infection in fewer than five pathogen generations.

In general, these results are well known for disease progress modeled by a logistic equation. Here we would like to draw attention to the way in which the ratio of disease severity in the two types (the functional divergence) changes in response to other factors, even as the ratio of the rate of disease increase for the two types remains the same. Fig. 1D illustrates the ratio of disease severity for each of the three examples over time. If the season is only long enough to allow five generations of pathogen reproduction, there is little difference between the three scenarios and estimates of the difference in disease severity between the two types increase over the five generations. After five generations, the difference in disease severity for the case of higher initial inoculum $(\mathrm{C})$ rapidly becomes obscured. For the case of higher overall growth rates with lower initial inoculum (A), the difference in disease severity becomes obscured after 10 generations.

Consider disease progress in the simplest form of mixture, a susceptible type mixed with an immune type (Fig. 2). When the proportion of the susceptible type in the mixture $p_{\mathrm{s}}=0.25$, the disease severity in the mixture increases following the logistic model until it reaches $25 \%$. Likewise, the weighted mean of the performance of the susceptible and resistant types when each is grown alone increases up to $25 \%$. As a result of "lost inoculum" in the mixture, the mixture does not experience appreciable disease for $R_{\mathrm{S}}=1$ until more than 10 generations 


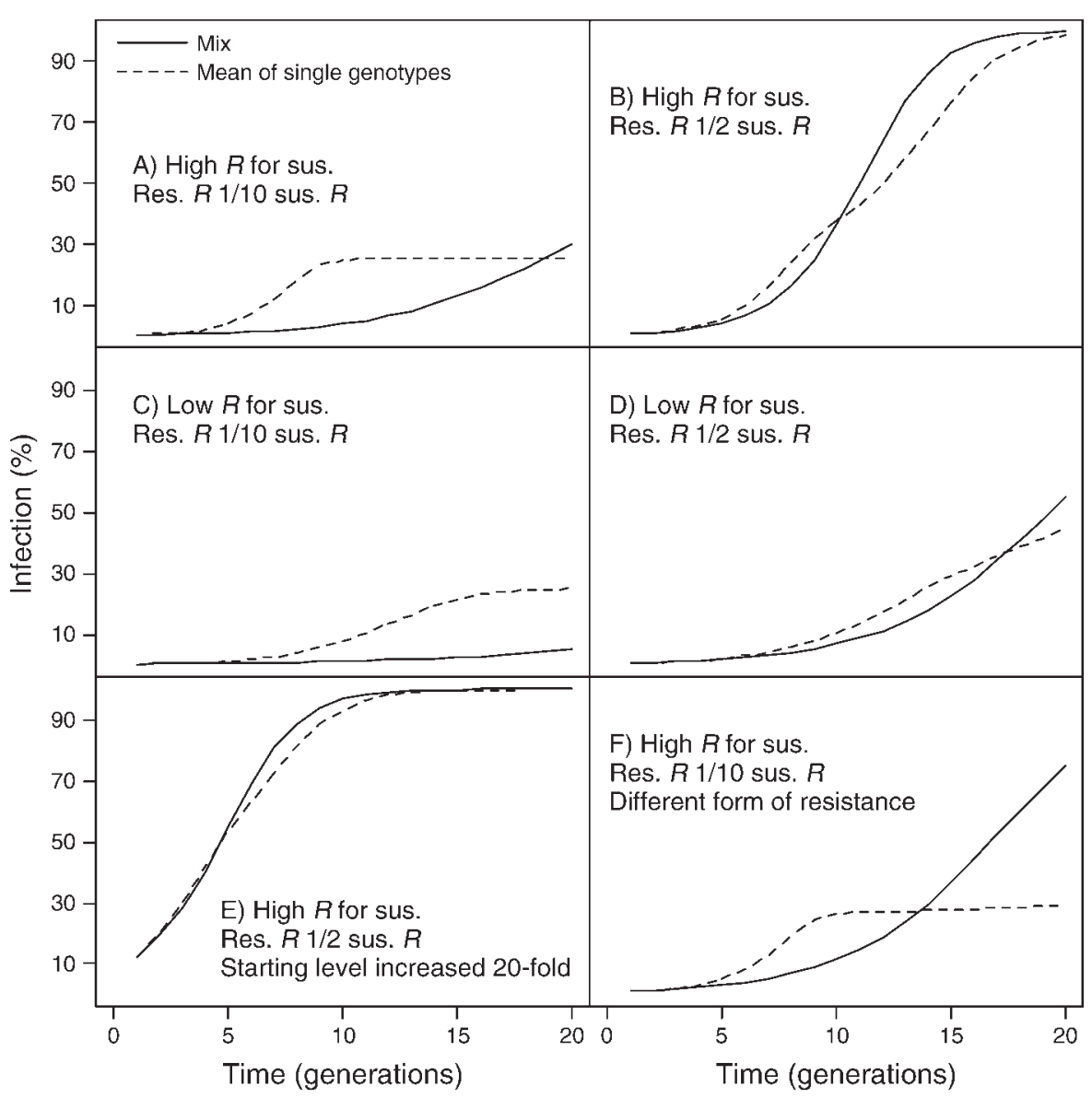

FIG. 3. Model disease progress curves for host mixtures of a susceptible type and a partially resistant type and for the mean of types growing separately. (A) Reference parameter combination with susceptible rate of disease progress as in Fig. $2 \mathrm{~A}$ and growth rate for resistance $1 / 10$ that of the susceptible type $\left(R_{\mathrm{S}}=1, R_{\mathrm{r}}=0.1, S=1\right)$. (B) Increased rate of disease progress for resistant type compared to (A) $\left(R_{\mathrm{S}}=1, R_{\mathrm{r}}=0.5, S=1\right)$. (C) Proportionately reduced growth rate for both susceptible and resistant types compared to (A) $\left(R_{\mathrm{s}}=0.5, R_{\mathrm{r}}=0.05, S=1\right)$. (D) Proportionately reduced growth rate for both susceptible and resistant types compared to (B) $\left(R_{\mathrm{S}}=0.5, R_{\mathrm{r}}=0.25, S=1\right)$. (E) Parameters as in panel (B) but with initial infection level increased 20 -fold $\left(R_{\mathrm{S}}=1\right.$, $R_{\mathrm{r}}=0.5, S=20$ ). (F) Parameters as in panel (A) but with resistance in the resistant type expressed through reduced sporulation per infection rather than through reduction of other components of resistance $\left(R_{\mathrm{s}}=1, R_{\mathrm{r}}=1, c_{\mathrm{r}}=0.1\right.$ [reduction in inoculum production per infection for partially resistant relative to susceptible type]).

have passed (Fig. 2A). This is reflected in the very low values of the RMR, even for greater than 10 generations (Fig. 2A). When the growth rate $R_{\mathrm{s}}$ increases to 1.5 , the effect of mixing for reduced disease begins to diminish after five generations and is nearly lost by 20 generations (Fig. 2B). When the initial infection level is increased from $S=1$ to $S=20$, the effect of mixing is reduced and is lost rapidly after five generations (Fig. 2C). Mixtures will result in reduced disease risk when enough generations have passed that disease is a potential problem, but not enough generations have passed for the system to be saturated with inoculum.

Moving to mixtures in which the resistant type is not immune, suppose $R_{\mathrm{r}}=0.1$ rather than 0 (Figs. 3A and $4 \mathrm{~A})$. For the same susceptible growth rate $\left(R_{\mathrm{s}}=1\right)$, the effect of the mixture on the susceptible type is comparable, but the resistant type is exposed to higher inoculum levels from the susceptible type such that it reaches higher rates of infection later than it would have if growing alone (Fig. 3A). As a result, the RMR increases after about 10 pathogen generations and goes above 1 at about 20 pathogen generations (Fig. 4A).

The effect of the overall level of resistance in a mixture and the effect of the ratio of rates of disease increase for the resistant and susceptible types were compared in a factorial with two levels of $R_{\mathrm{S}}(1$ and 0.5$)$ and two levels of the ratio $R_{\mathrm{r}} / R_{\mathrm{s}}(0.1$ and 0.5$)$. The high $R_{\mathrm{s}}$, high difference in resistance case was just discussed as giving similar results to the simple mixture of a susceptible with an immune type (Figs. $3 \mathrm{~A}$ and $4 \mathrm{~A}$ ). The high $R_{\mathrm{s}}$, low difference in resistance case $\left(R_{\mathrm{s}}=1\right.$ and $\left.R_{\mathrm{r}}=0.5\right)$ demonstrates little reduction in disease during mixing and a greater increase in disease in mixture after 10 generations (Figs. 3B and 4B). The low $R_{\mathrm{s}}$, high difference in resistance case $\left(R_{\mathrm{S}}=0.5, R_{\mathrm{r}}=0.05\right)$ demonstrates a steady decrease in RMR to 10 genera- 


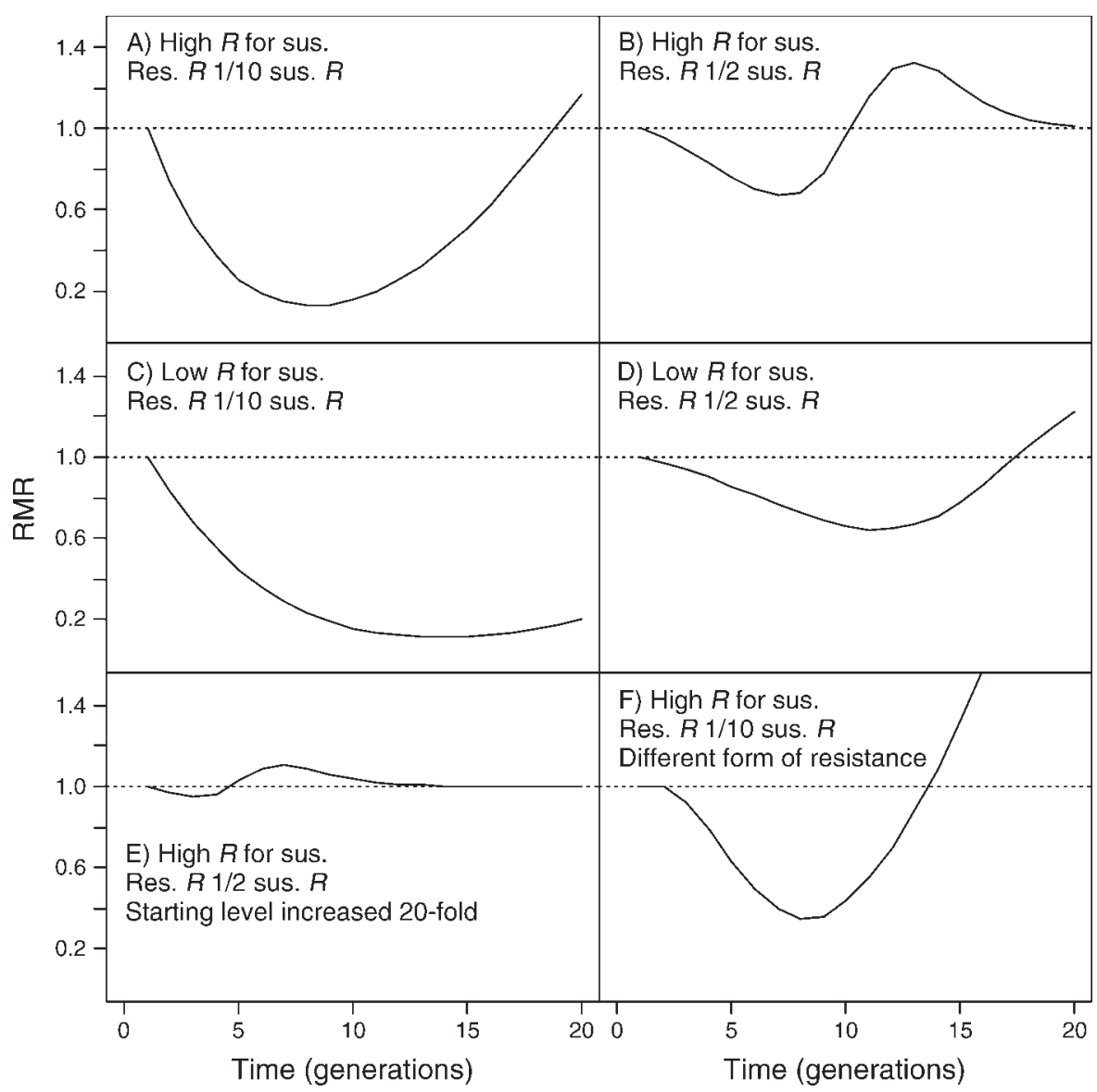

FIG. 4. Relative mixture response (RMR; ratio of late-blight severity in mixture over the weighted mean late-blight severity in single-genotype stands) time series corresponding to Fig. 3.

tions and then maintenance of the low RMR through 20 generations (Figs. 3C and 4C). The low $R_{\mathrm{s}}$, low difference in resistance case exhibits only a minor difference between disease severity in mixture compared to types grown individually across 20 generations (Figs. $3 \mathrm{D}$ and 4D). When the starting infection level is increased from $S=1$ to $S=10$ in the high $R_{\mathrm{s}}$, high difference in resistance case, this serves to further obscure the effect of mixing (Figs. 3E and 4E). If the resistance in the resistant type is expressed through reduced inoculum production per infection rather than through other resistance components (i.e., reduced $c_{\mathrm{r}}$ rather than reduced $R_{\mathrm{r}}$ ), then the RMR is reduced less during early phases of the epidemic and becomes much greater than 1 after sufficient generations pass (Figs. $3 \mathrm{~F}$ and $4 \mathrm{~F}$ ). Note that the disease progress of a stand of a single resistant type with parameters $R_{\mathrm{r}}=1$ and $c_{\mathrm{r}}=0.1$ is the same as the disease progress in a stand of a single resistant type with parameters $R_{\mathrm{r}}=0.1$ and $c_{\mathrm{r}}=1$. These are simply different ways of partitioning the resistance parameters.

\section{Peruvian field study results}

Overall, the effects of diversity on disease severity were greater during the disease non-conducive La Niña season compared to the El Niño season. Mixture effects were generally greater at shorter-season Huancayo sites compared to longer-season Cajamarca sites. The specific combination of cultivars in mixtures often appeared to influence the size of the diversity effect.

In the El Niño season, 1997-1998, significant reductions in disease were observed near shorter-season Huancayo for the Chagllina-Tomasa mixture (Fig. 5). There, disease severity was significantly reduced in mixture for the susceptible Tomasa, but there was a corresponding disease increase in mixture for the relatively resistant Chagllina. The combination of the two effects resulted in only a small decrease in disease for the mixture as a whole. The only statistically significant result at sites near Cajamarca was also a relatively small change. For the Amarilis-Yungay mixture, disease severity for the susceptible Yungay was reduced in mixtures, but disease severity for the resistant Amarilis was increased in mixtures (Fig. 5). Even though disease severity was increased on Amarilis in mixtures, there was still a large reduction in disease severity for the Amarilis-Yungay mixture overall because Amarilis had much higher resistance than Chagllina. There was an estimated disease severity 

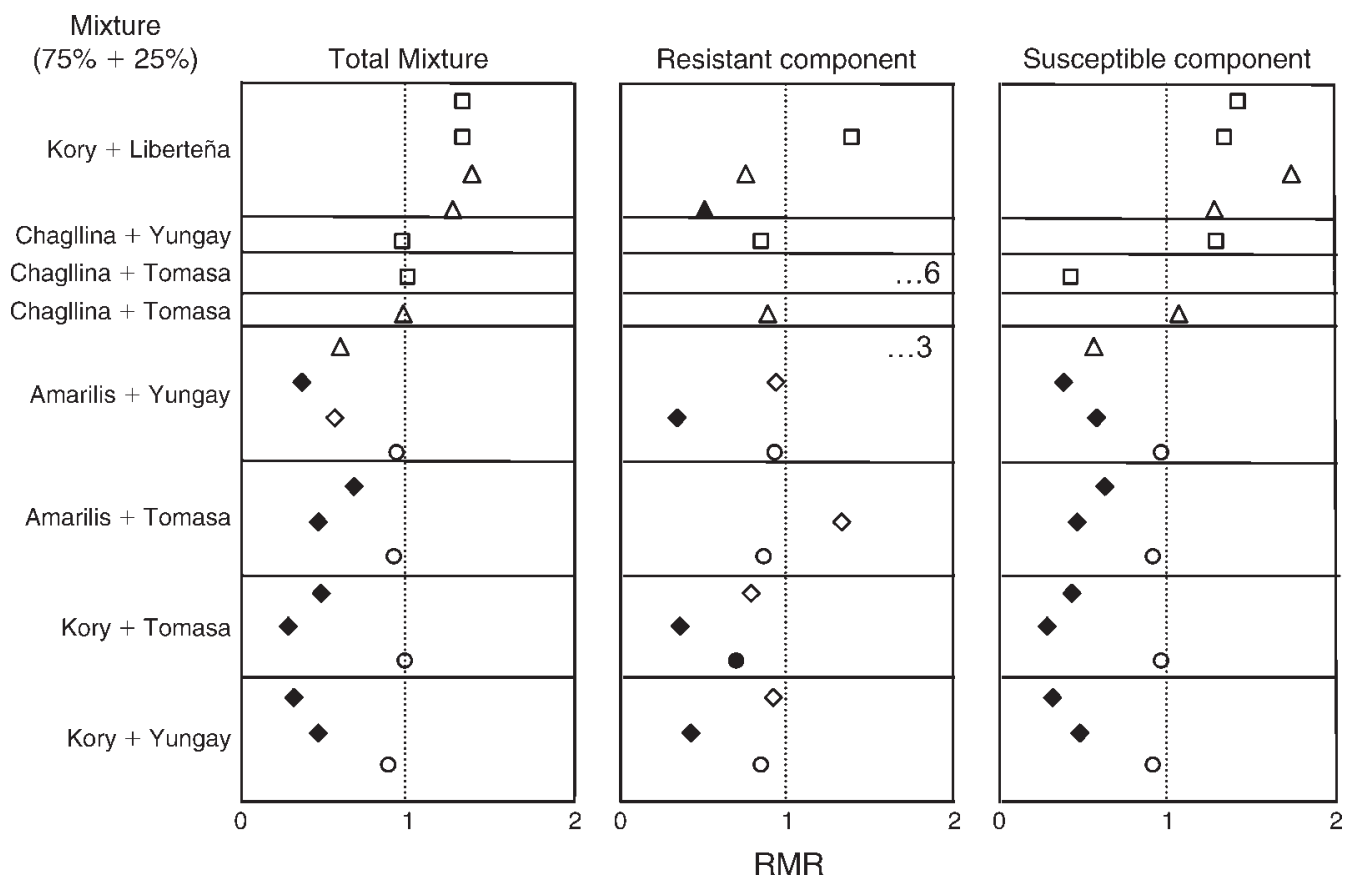

FIG. 5. The relative mixture response (RMR; ratio of late-blight severity in mixture over late-blight severity in single-genotype stands) for each of the potato mixtures studied near Huancayo and Cajamarca, Peru. If there was no host-diversity effect, RMR $=$ 1. The RMR was calculated for the mixture as a whole and for each of the resistant and susceptible components. Squares indicate Huancayo sites in the El Niño year, diamonds indicate Huancayo sites in the La Niña year, triangles indicate Cajamarca sites in the El Niño year, and circles indicate the Cajamarca site in the La Niña year. When a number is printed in place of a symbol, the number gives the observed RMR, which was off the scale of the figure. Statistical significance of the host-diversity effect, based on linear contrasts, is indicated for the RMR of the separate components. Solid symbols indicate that the effect was statistically significant with $P<0.05$.

increase due to host diversity for the Kory-Liberteña mixture at each site in 1997-1998, though the effect was not statistically significant at any site (Fig. 5).

In the 1998-1999 La Niña season, the same mixtures were repeated at each site, allowing for more direct comparisons. The resistant cultivars, Amarilis and Kory, had only very low infection near Huancayo (Fig. 5). The Amarilis-Yungay mixture was repeated and in this season disease severity was not increased in mixture for Amarilis. For Amarilis in mixture with Tomasa, however, there was an estimated increase in disease severity in mixture at one site near Huancayo (Fig. 5). This increase was not statistically significant and was based mostly on the large increase in infection in Amarilis in one experimental replicate (data not shown). At the sites near Huancayo, there was significant disease reduction in mixture for the susceptible component in all four mixtures and for the resistant component, as well, in some cases (Fig. 5). At the site near longer-season Cajamarca, there was a statistically significant reduction in disease in mixture for the susceptible cultivar only for the Amarilis-Tomasa mixture, and the magnitude of reduction was relatively small (Fig. 5).

The host-diversity effect on a given potato cultivar when paired with different cultivars was also compared for the 1998-1999 season. There was evidence for a difference in host-diversity effects on the susceptible Tomasa in the Amarilis-Tomasa vs. Kory-Tomasa mixtures at both Huancayo sites $(P=0.01$ for $\mathrm{H}-\mathrm{S} 99$; $P=0.05$ for H-P99) but not at the Cajamarca site $(P=$ 0.27 for C-S99). There was no evidence for a difference in host-diversity effects on the susceptible Yungay in Amarilis-Yungay vs. Kory-Yungay mixtures at any of the three sites $(P>0.69$ for all three); neither was there a difference for the resistant Amarilis or the resistant Kory at any of the three sites.

\section{Comparison of host diversity effects in Peru, United States, and Ecuador}

There was a general tendency for greater hostdiversity effects for reduced disease severity at the sites with shorter seasons/lower estimated regional inoculum loads (Fig. 6). Responses were quite variable for some locations, however, particularly for Huancayo in 1998 and Cajamarca in 1998. The relationship between seasonality/inoculum ranking and RMR was statistically significant when analyzed alone $(P=0.008)$, but not when the ratio of the AUDPC in the susceptible genotype to the AUDPC in the resistant genotype was also included in the analysis $(P=0.28)$. There was no trend within a site-year, but over all mixtures there was a clear trend toward greater host-diversity effects for reduced disease for mixtures with greater differences in 
FIG. 6. The relative mixture response (RMR; ratio of late-blight severity in mixture over lateblight severity in single-genotype stands) for each site-mixture-year combination vs. the estimated level of outside inoculum. If there was no hostdiversity effect, $R M R=1$. The ranking of the level of inoculum was predicted qualitatively based on the climate of an area and the degree of seasonality of potato production there (see Table 4). Each point represents the mean of four replicate plots of a particular potato mixture at a particular farm. Results from previous studies in Corvallis, Oregon, USA (Garrett and Mundt 2000b), and Quito, Ecuador (Garrett et al. 2001), are also included.

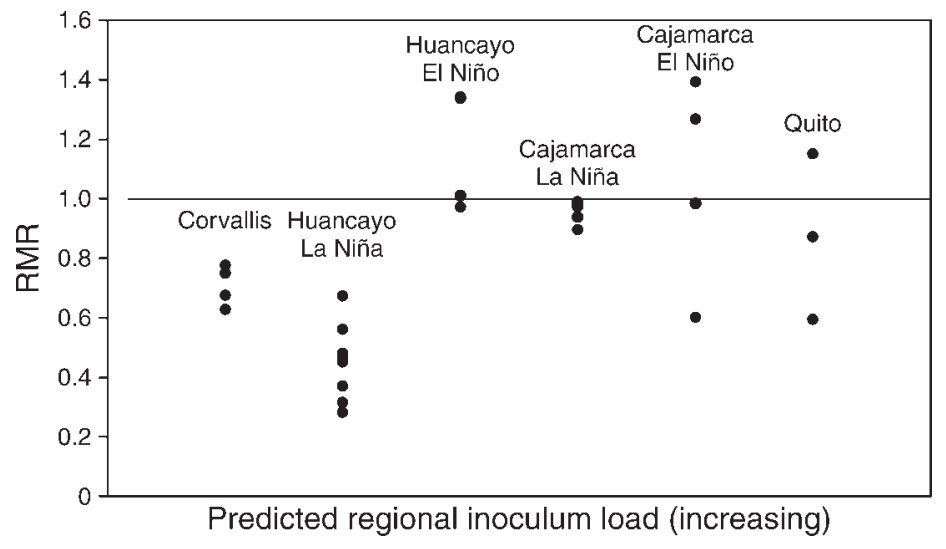

levels of resistance among components (higher functional divergence) ( $P=0.001$; Fig. 7$)$. One exception was the Kory-Liberteña mixture at C-P98, which had a large difference in resistance between components, but a (statistically nonsignificant) host-diversity effect for increased disease severity. The other exception was the Chagllina-Yungay mixture at H-P98, which had a small difference in resistance between components, but a large (again, statistically nonsignificant) host-diversity effect for reduced disease.

\section{Discussion}

Our first hypothesis was that greater functional divergence in mixtures will result in a greater effect of diversity on disease risk. We defined functional divergence in terms of a greater difference in disease resistance phenotypes between components grown individually. This hypothesis was generally supported by both the model scenarios we considered and in the analysis of late blight in potato mixtures across a climatic gradient. The analysis of functional divergence is complicated by the fact that the disease resistance phenotypes change over time when host types are not immune, with differences between them eventually becoming obscured as severity in the resistant type "catches up" to severity in the susceptible type (Fig. 1D). Functional divergence increases initially as severity in the susceptible type increases proportionately more rapidly than in the resistant type. For a mixture of a susceptible and an immune genotype (high functional divergence), the biodiversity effect to reduce disease (indicated by reductions in the relative mixture response [RMR]) declines initially as disease severity in the monoculture increases rapidly (Fig. 2). As disease in the susceptible monoculture approaches its maximum level and disease severity in the mixture rises, the reduction in disease due to mixing begins to decline. When the resistant component of a two-genotype mixture is not immune (Figs. 3 and 4), this simple model predicts increased infection in the resistant type when it is in mixture compared to monoculture. The outcome of this structure is that the disease severity in mixture can eventually surpass the weighted mean severity for monocultures, if enough pathogen generations pass. Our model does not incorporate the possibility of benefit for both mixture components, though a benefit of mixing was observed for the resistant component of some of the potato mixtures and has been reported in other systems such as rice blast (Zhu et al. 2000). In the Peruvian field studies, functional divergence ranged widely, with greater functional divergence for a given mixture at the shorter-season Huancayo sites (Table 3). The observed differences are probably explained in part by different epidemic ages for the dif-
FIG. 7. The relative mixture response (RMR; ratio of late-blight severity in mixture over lateblight severity in single-genotype stands) for each site-mixture-year combination vs. a measure of functional divergence $\left(\log _{10}\right.$ [AUDPC of susceptible mixture component/AUDPC of resistant mixture component]); AUDPC is the area under the disease progress curve. If there was no hostdiversity effect, $\mathrm{RMR}=1$. Names of the sites are also included near the centroid for observations from that site.

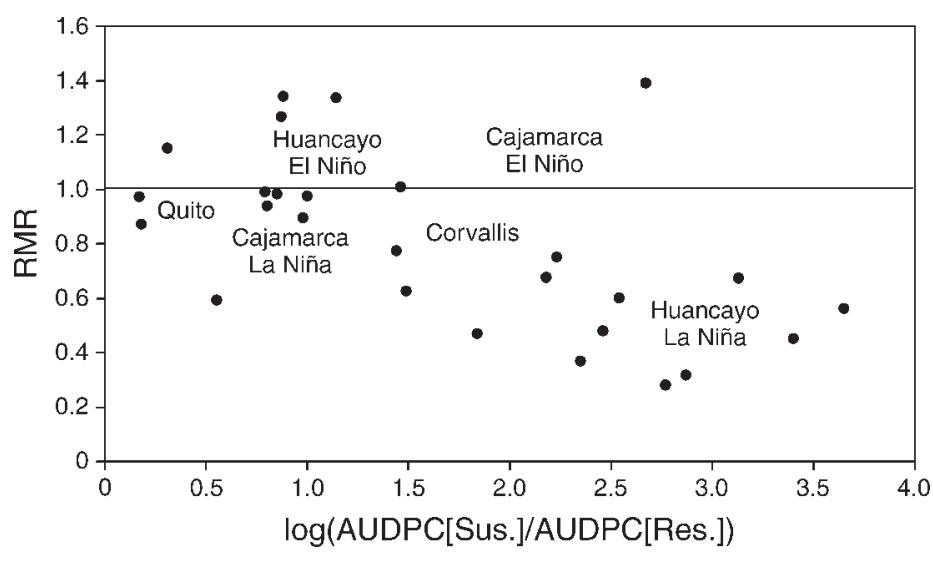




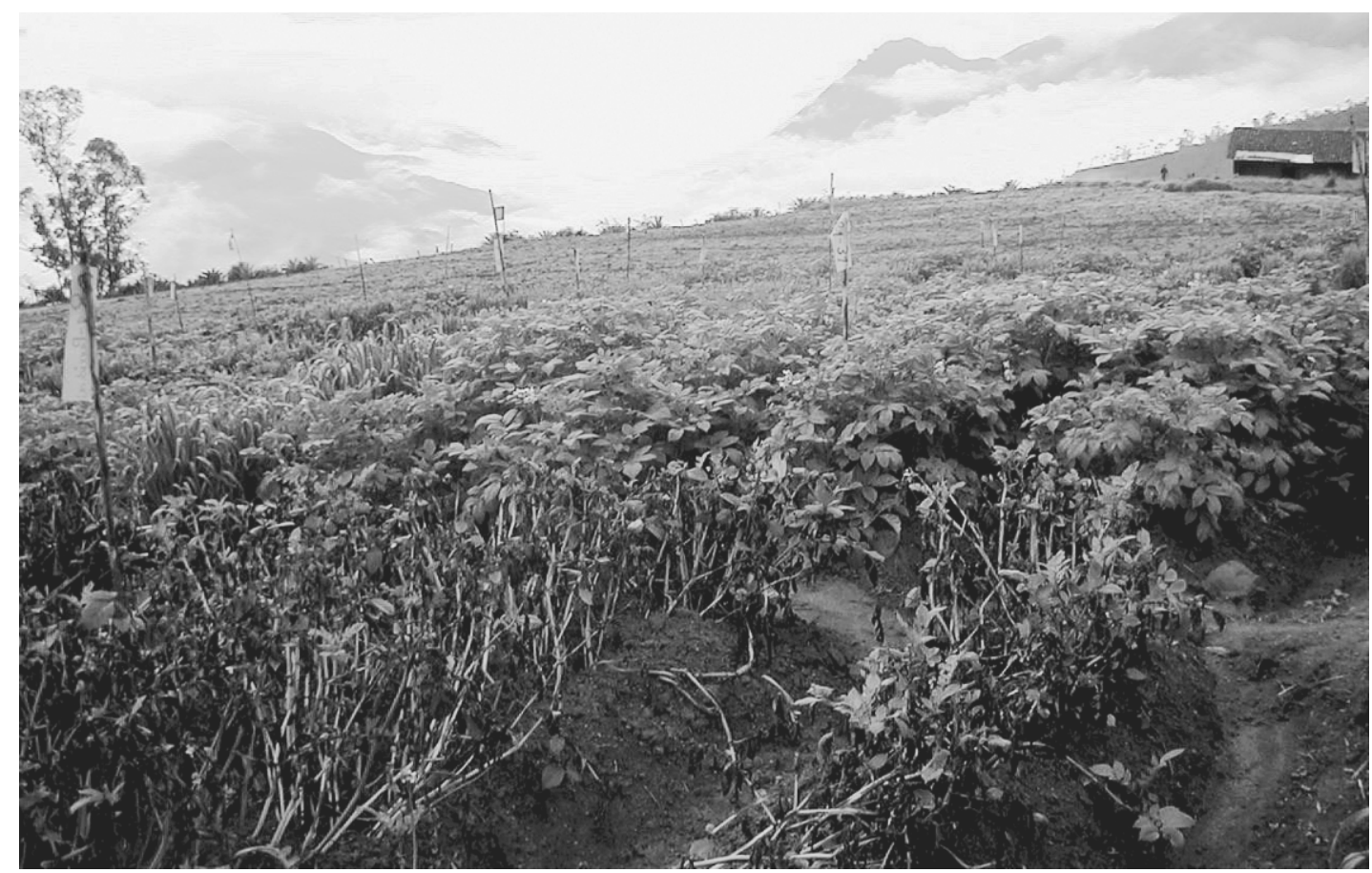

Plate 1. Peruvian potato field illustrating damage from potato late blight, caused by Phytophthora infestans, in the foreground. Photo credit: R. J. Nelson.

ferent site-years, as inoculum was introduced earlier or later in the season. In comparisons across countries, the greater disease reduction associated with higher functional divergence was clear (Fig. 7).

The form of resistance may also be important for determining the benefit of mixtures; when the resistance is specifically in the form of reduced inoculum production per infection, the presence of the resistant variety in mixtures offers less benefit. In Peru, the Kory-Liberteña mixture showed a somewhat consistent increase in disease in mixtures compared to the mean for single genotype monocultures, but evaluation of spores per lesion produced in vitro (J. Smith, unpublished data) and lesions per spore produced in the field (data not shown) did not indicate that incompatible patterns of components of resistance explained this response (as in Jeger $1981 a, b)$. On the other hand, in some cases there was evidence of reduced disease in the more resistant variety in mixtures, probably either because the varieties differed in forms of disease resistance, induced resistance as a result of exposure to inoculum from the other component, or because of an altered microclimate (Garrett and Mundt 1999).

Our second hypothesis was that longer seasons, and associated higher inoculum loads, would result in lower benefits from host biodiversity. This hypothesis was also generally supported in both the model scenarios and the field studies. We evaluated this in our model in terms of the effects of higher starting inoculum loads and a higher number of pathogen generations. If the rate of increase for disease in both resistant and susceptible types is increased proportionately by more diseaseconducive environmental conditions, the initial reduction in functional divergence holds over a shorter period of time. If the initial infection level is higher because of higher regional inoculum loads, the benefit of mixing is never as great and the decrease in benefit occurs sooner. The functional divergence of a mixture is a function of both genotypic resistance and the environmental conditions (including regional inoculum load) at the local site where disease severity is measured. For this reason, the effects of regional inoculum load and the ratio of disease resistance phenotypes cannot be separated cleanly in analyses. For example, if the genotypically susceptible component exhibits higher phenotypic susceptibility because of a disease-conducive environment, the loss of benefit from mixing occurs sooner. In the field studies, there was a general trend for a greater beneficial effect of mixtures at sites with shorter seasons and less diseaseconducive conditions, where there was likely a lower regional inoculum load (Fig. 6). This is a logical outcome. For locations such as Quito, where potatoes are grown year-round, the regional inoculum load can increase until another factor such as reduced moisture availability becomes limiting for pathogen reproduction. Corvallis is somewhat more complicated: while the growing season is brief, pathogen generation times appear to be shorter than in many areas (data not shown). In areas with limited growing seasons, inoculum buildup is strictly limited by host availability. However, the 
relationship between seasonality and biodiversity effect may be explained to a great extent by the greater functional divergence observed in shorter-season regions (Fig. 7).

For some of the mixtures evaluated in Peru, host biodiversity reduced late blight risk when varieties were grown together compared to being grown separately, suggesting that the use of mixtures can be a useful disease management component in these systems. Previous studies have shown that host diversity may be most effective for late blight management when combined with other management components, such as fungicide applications (Garrett et al. 2001, Pilet et al. 2006). Mixtures such as the ones evaluated in this study may be of most practical use when susceptible varieties are of higher economic value, while resistant varieties are lower value. This is often the case when new forms of resistance are incorporated into varieties but are not yet combined with a full range of desirable traits such as culinary value. Mixtures may be most effective if they combine genotypes with different forms of resistance, such that pathogen populations are partitioned between the genotypes and all genotypes may experience reduced disease. While these experimental mixtures were composed of only two genotypes for simplicity, mixtures of larger numbers of genotypes may be more useful for disease reduction (Mundt 2002, Skelsey et al. 2005), though good strategies are needed for formulating the most useful complex mixtures (Garrett and Cox 2008). Our field results suggest that the utility of mixtures for reducing disease will vary over the course of the season, as discussed by Wolfe and Barrett (1980), and as a function of the disease-conduciveness of environmental conditions. The benefits of use of mixtures will be briefer if the rate of disease increase is sped up by higher initial infections or more disease-conducive conditions. Conversely, if the rate of disease increase is very low or few pathogen generations fit in a growing season, the impact of mixtures may be small. The effects of host genotype on yield were less consistent than the effect on disease (data not shown), perhaps because of the many types of interactions possible between the potato genotypes and between the genotypes and environmental factors.

Our model was designed to examine the general effects of functional divergence and environment on disease progress. It has the virtue of simplicity, but several other factors also contribute to disease risk. Potato late blight risk has frequently been modeled as a function of detailed weather variables (e.g., AndradePiedra et al. 2005). For late blight and some other wellstudied pathosystems, the "disease conduciveness" of a season can be fairly well defined and could be incorporated in the description of any particular location where weather data are available. The model we developed is not spatially explicit, rather it includes two general types of spatial configuration: a scenario where types are mixed together and a scenario where types are distant enough that there is no explicit inoculum exchange. More detailed spatial structure can also inform predictions of the effects of biodiversity on disease risk, both in terms of generalized spatial configurations (Mundt et al. 1986, van den Bosch et al. 1990, Garrett and Mundt 1999, Park et al. 2002, Bouws and Finckh 2008) and landscape structures, such as the tendency for the root pathogen Phytophthora lateralis, to disperse along rivers and through human transportation networks (Jules et al. 2002). Animal disease epidemiology has often emphasized the distinction between frequency-dependent and density-dependent transmission of disease (Begon et al. 2002), but, since agricultural plant systems have often been adapted for an optimal planting density, the frequency and density of susceptible hosts generally change in tandem. In the context of our simple model, the genetic structure of pathogen populations has effects comparable to those of environmental disease conduciveness: pathogen genotypes with more rapid reproduction will result in faster epidemics with resulting changes in the effects of host diversity on disease risk. Similarly, the initial inoculum levels may also be influenced by factors such as the level of effectiveness of field sanitation, the removal of infected plant parts that serve as an inoculum source.

In their review of genetic diversity and ecology, Hughes et al. (2008) identified three general areas for future development. First, the relationship between genotypic and phenotypic diversity needs further exploration. For systems in which the genetic basis for resistance is understood to some extent, genotypic diversity can be evaluated in terms of not only host genotype richness (the number of genotypes), but the variance in host genotypic and phenotypic characters, where these can be measured in terms of functional diversity and divergence as well (Garrett et al. 2006b). Second, what is the relative importance of genotypic diversity compared to other mechanisms that drive ecological processes? In our system, we can compare the effects of genotypic diversity and species diversity, where non-hosts can produce the greatest functional divergence. In systems of more complex host community structure, how does the likelihood of pathogen-sharing change as a function of host species relatedness (Gilbert and Webb 2007)? When pathogens are shared among hosts that play different epidemic roles, as for $P$. ramorum (Rizzo et al. 2005) where some species may act as reservoirs, more complex models are required. We have also demonstrated the role of environmental factors in determining functional divergence. Third, there is a need for explicit tests of the potential mechanisms underlying genotypic diversity effects on phenotypes. We have demonstrated how disease resistance phenotypes vary with environment, producing complex interactions among functional divergence, environment, and biodiversity effects.

These model and field results illustrate several facets of the relationships among disease severity and the components of the disease triangle: host (including host 
diversity), environment (including season length), and pathogen. These relationships are likely to be similar for managed systems, where host diversity is deployed following a strategy, as well as in nonagricultural systems where host diversity occurs without direct human planning. At a local scale, for example within a field, the structure of host diversity may reduce likely disease severity. At a regional scale, higher host diversity may also reduce regional disease severity. As a basic principle, disease severity will tend to be higher at both scales the more disease-conducive the environment is, the longer the season, the more susceptible the host population, the lower the host functional divergence, and the more rapidly the pathogen population reproduces. These factors can also reduce the impact of host diversity on disease severity if they increase the rate of disease increase to the point that the system is effectively saturated with inoculum. The quality of disease management at a regional scale can determine how difficult management at a local scale will be. If the regional pathogen load saturates a field with inoculum, not only will the use of mixtures be less beneficial, but so will other local practices intended to reduce local inoculum loads, such as improved local sanitation and the use of host resistance based on reduced inoculum production per infection. Seasonal limits can keep the growth of regional inoculum loads in check. For regions where changes in climate produce longer disease-conducive seasons, the use of some local management methods may be compromised at the same time that the need for management intensifies (Garrett et al. 2006a). Conversely, where climates change to reduce regional inoculum loads, well-structured mixtures may become more useful for disease management, and epidemic initiation may be delayed. And where longer seasons are combined with increased intervals of environmental conditions that are otherwise less conducive to disease (such as drought in the case of some diseases), the outcome for disease management will be more difficult to predict. Particular weather conditions may also favor long-distance dispersal events such as spore showers that can play pivotal roles in epidemics. Similar interactions are likely to occur for agricultural systems and for natural systems, so that if the inoculum load shifts with climate change, the effects of host diversity on epidemics may also be altered, producing a type of feedback for epidemic risk.

\section{ACKNOWLEDGMENTS}

We thank the reviewers for very helpful comments. For assistance with the field research, we thank R. Orrego, W. G. Perez, C. Sanabria, A. M. Smith, J. Smith, J. C. Taza, and H. Luna Vilchez. We also gratefully acknowledge support by USAID linkage funds, by the USAID for the Sustainable Agriculture and Natural Resources Management Collaborative Research Support Program (SANREM CRSP) under terms of Cooperative Agreement Award No. EPP-A-00-04-00013-00 to the Office of International Research and Development at Virginia Tech and for the IPM CRSP (No. EPP-A00-04-00016-00), by NSF Grants DEB-0130692 and DEB0516046, by NSF grant EF-0525712 as part of the joint NSF-
NIH Ecology of Infectious Disease program, and by the Kansas State Experiment Station (Contribution No. 08-131-J).

\section{Literature Cited}

Andrade-Piedra, J. L., G. A. Forbes, D. Shtienberg, N. J. Grunwald, M. G. Chacon, M. V. Taipe, R. J. Hijmans, and W. E. Fry. 2005. Qualification of a plant disease simulation model: performance of the LATEBLIGHT model across a broad range of environments. Phytopathology 95:1412-1422.

Andrivon, D., J. M. Lucas, and D. Ellisseche. 2003. Development of natural late blight epidemics in pure and mixed plots of potato cultivars with different levels of partial resistance. Plant Pathology 52:586-594.

Begon, M., M. Bennett, R. G. Bowers, N. P. French, S. M. Hazel, and J. Turner. 2002. A clarification of transmission terms in host-microparasite models: numbers, densities and areas. Epidemiology and Infection 129:147-153.

Bouws, H., and M. R. Finckh. 2008. Effects of strip intercropping of potatoes with non-hosts on late blight severity and tuber yield in organic production. Plant Pathology 57:916-927.

Crissman, C. C., P. Espinosa, C. E. H. Ducrot, D. C. Cole, and F. Carpio. 1998. The case study site: physical health and potato farming systems in Carchi province. Pages 85-120 in C. C. Crissman, J. M. Antle, and S. M. Capalbo, editors. Economic, environmental, and health tradeoffs in agriculture: pesticides and the sustainability of Andean potato production. Kluwer Academic Publishers, Dordrecht, The Netherlands.

Diaz, S., A. J. Symstad, F. S. Chapin, III, D. A. Wardle, and L. F. Huenneke. 2003. Functional diversity revealed by removal experiments. Trends in Ecology and Evolution 18: 140-146.

Finckh, M. R., E. S. Gacek, H. Goyeau, C. Lannou, U. Merz, C. C. Mundt, L. Munk, J. Nadziak, A. C. Newton, C. de Vallavieille-Pope, and M. S. Wolfe. 2000. Cereal variety and species mixtures in practice, with emphasis on disease resistance. Agronomie 20:813-837.

Fridley, J. D. 2001. The influence of species diversity on ecosystem productivity: how, where, and why? Oikos 93:514526.

Fry, W. E., and S. B. Goodwin. 1997. Resurgence of the Irish potato famine fungus. BioScience 6:363-371.

Garrett, K. A., and C. M. Cox. 2008. Applied biodiversity science: managing emerging diseases in agriculture and linked natural systems using ecological principles. Pages 368-386 in R. Ostfeld, F. Keesing, and V. Eviner, editors. Infectious disease ecology: effects of ecosystems on disease and of disease on ecosystems. Princeton University Press, Princeton, New Jersey, USA.

Garrett, K. A., S. P. Dendy, E. E. Frank, M. N. Rouse, and S. E. Travers. 2006a. Climate change effects on plant disease: genomes to ecosystems. Annual Review of Phytopathology 44:489-509.

Garrett, K. A., S. H. Hulbert, J. E. Leach, and S. E. Travers. $2006 b$. Ecological genomics and epidemiology. European Journal of Plant Pathology 115:35-51.

Garrett, K. A., and C. C. Mundt. 1999. Epidemiology in mixed host populations. Phytopathology 89:984-990.

Garrett, K. A., and C. C. Mundt. 2000a. Effects of planting density and cultivar mixture composition on stripe rust of wheat: an analysis accounting for limits to the replication of controls. Phytopathology 90:1313-1321.

Garrett, K. A., and C. C. Mundt. 2000b. Host diversity can reduce potato late blight severity for focal and general patterns of primary inoculum. Phytopathology 90:1307-1312.

Garrett, K. A., R. J. Nelson, C. C. Mundt, G. Chacon, R. E. Jaramillo, and G. A. Forbes. 2001. The effects of host diversity and other management components on epidemics of potato late blight in the humid highland tropics. Phytopathology 91:993-1000. 
Gilbert, G. S., and C. O. Webb. 2007. Phylogenetic signal in plant pathogen-host range. Proceedings of the National Academy of Sciences (USA) 104:4979-4983.

Hansen, E. M. 2008. Alien forest pathogens: Phytophthora species are changing world forests. Boreal Environment Research 13:33-41.

Hooper, D. U., et al. 2005. Effects of biodiversity on ecosystem functioning: a consensus of current knowledge. Ecological Monographs 75:3-35.

Hughes, A. R., B. D. Inouye, M. T. J. Johnson, N. Underwood, and M. Vellend. 2008. Ecological consequences of genetic diversity. Ecology Letters 11:609-623.

Jeger, M. J., E. Griffiths, and D. G. Jones. 1981a. Disease progress of non-specialized fungal pathogens in intraspecific mixed stands of cereal cultivars. I. Models. Annals of Applied Biology 98:198-198.

Jeger, M. J., D. G. Jones, and E. Griffiths. 1981b. Disease progress of non-specialised fungal pathogens in intraspecific mixed stands of cereal cultivars. II. Field experiments. Annals of Applied Biology 98:199-210.

Jules, E. S., M. J. Kauffman, W. D. Ritts, and A. L. Carroll. 2002. Spread of an invasive pathogen over a variable landscape: a nonnative root rot on Port Orford cedar. Ecology 83:3167-3181.

Keesing, F., R. D. Holt, and R. S. Ostfeld. 2006. Effects of species diversity on disease risk. Ecology Letters 9:485-498.

Leonard, K. J. 1969. Factors affecting rates of stem rust increase in mixed plantings of susceptible and resistant oat varieties. Phytopathology 59:1845-1969.

Leung, H., Y. Zhu, I. Revilla Molina, J. X. Fan, H. Chen, I. Pangga, C. Vera Cruz, and T. W. Mew. 2003. Using genetic diversity to achieve sustainable rice disease management. Plant Disease 87:1156-1169.

Lima, M. A., L. A. Maffia, R. W. Barreto, and E. S. G. Mizubuti. 2009. Phytophthora infestans in a subtropical region: survival on tomato debris, temporal dynamics of airborne sporangia and alternative hosts. Plant Pathology 58: 87-99.

Madden, L.V., G. Hughes, and F. van den Bosch. 2007. The study of plant disease epidemics. APS Press, St. Paul, Minnesota, USA.

Mason, N. W. H., D. Mouillot, W. G. Less, and J. B. Wilson. 2005. Functional richness, functional evenness and functional divergence: the primary components of functional diversity. Oikos 111:112-118.

Mitchell, C. E., D. Tilman, and J. V. Groth. 2002. Effects of grassland plant species diversity, abundance, and composition on foliar fungal disease. Ecology 83:1713-1726.

Mundt, C. C. 2002. Use of multiline cultivars and cultivar mixtures for disease management. Annual Review of Phytopathology 40:381-410.

Mundt, C. C., K. J. Leonard, W. M. Thal, and J. H. Fulton. 1986. Computerized simulation of crown rust epidemics in mixtures of immune and susceptible oat plants with different genotype unit areas and spatial distributions of initial disease. Phytopathology 76:590-598.

Park, A. W., S. Gubbins, and C. A. Gilligan. 2002. Extinction times for closed epidemics: the effects of host spatial structure. Ecology Letters 5:747-755.

Phillips, S. L., M. W. Shaw, and M. S. Wolfe. 2005. The effect of potato variety mixtures on epidemics of late blight in relation to plot size and level of resistance. Annals of Applied Biology 147:245-252.

Pilet, F., G. Chacón, G. A. Forbes, and D. Andrivon. 2006. Protection of susceptible potato cultivars against late blight in mixtures increases with decreasing disease pressure. Phytopathology 96:777-783.

Rhoades, R. E., and A. J. Bebbington. 1990. Mixing it up: variations in Andean farmers' rationales for intercropping of potatoes. Field Crops Research 25:145-156.

Rizzo, D. M., M. Garbelotto, and E. A. Hansen. 2005. Phytophthora ramorum: integrative research and management of an emerging pathogen in California and Oregon forests. Annual Review of Phytopathology 43:309-335.

Skelsey, P., W. A. H. Rossing, G. J. T. Kessel, J. Powell, and W. van der Werf. 2005. Influence of host diversity on development of epidemics: an evaluation and elaboration of mixture theory. Phytopathology 95:328-338.

Smith, M. J., A. White, X. Lambin, J. A. Sherratt, and M. Begon. 2006. Delayed density-dependent season length alone can lead to rodent population cycles. American Naturalist 167:695-704.

Travers, S. E., M. D. Smith, J. Bai, S. H. Hulbert, J. E. Leach, P. S. Schnable, A. K. Knapp, G. Milliken, P. Fay, A. Saleh, and K. A. Garrett. 2007. Ecological genomics: making the leap from model systems in the lab to native populations in the field. Frontiers in Ecology and the Environment 5:19-24. van den Bosch, F., M. A. Verhaar, A. A. M. Buiel, W. Hoogkamer, and J. C. Zadoks. 1990. Focus expansion in plant disease. 4. Expansion rates in mixtures of resistant and susceptible hosts. Phytopathology 80:598-602.

Whitham, T. G., et al. 2006. A framework for community and ecosystem genetics: from genes to ecosystems. Nature Reviews Genetics 7:510-523.

Wolfe, M. S. 1985. The current status and prospects of multiline cultivars and variety mixtures for disease resistance. Annual Review of Phytopathology 23:251-273.

Wolfe, M. S., and J. A. Barrett. 1980. Can we lead the pathogen astray? Plant Disease 64:148-155.

Zhu, Y., et al. 2000. Genetic diversity and disease control in rice. Nature 406:718-722.

Zhu, Y. Y., H. Fang, Y. Y. Wang, J. X. Fan, S. S. Yang, T. W. Mew, and C. C. Mundt. 2005. Panicle blast and canopy moisture in rice cultivar mixtures. Phytopathology 95:433438.

Zwankhuizen, M. J., F. Govers, and J. C. Zadoks. 1998 Development of potato late blight epidemics: disease foci, disease gradients and infection sources. Phytopathology 88: $754-763$. 